\title{
Girl - Child Education as a Panacea for National Development and Sustainability
}

\author{
Nwokolo Chinyelu, Nwokolo Somti \\ Nnamdi Azikiwe University, Nigeria
}

\begin{abstract}
Education is the bedrock for any sustainable development. This is because Education is an inevitable tool and its mastery is a basic condition for Sustainability and Development of any emergent world. In Africa and with reference to Nigeria, despite the fact that Education is a veritable tool the girl child is still lagging in formal education This may be attributed to some factors including; attitude, culture, beliefs, parental factors, societal norms and low self concept. It is for the above reasons that counselling intervention strategies are needed so that our young ones will have a better chance of changing the society through education. It is against this backdrop that the study was carried out. The study adopted the descriptive study design. The study was carried out in the south east states of Nigeria. The south east is made up of five states; namely Anambra, Abia, Ebonyi, Enugu and Imo. The population comprised all the counselors in their various states in the south east, Nigeria. The sample is 500 counsellors from the five states in the south east. The instrument for data collection was a researcher designed structured questionnaire. The instrument was face and content validated by two experts from Guidance and Counselling Department of Nnamdi Azikiwe University, Awka, Anambra State, measurement and evaluation in Education Foundation Department of Ebonyi State University, Abakiliki, Ebonyi State. The reliability of the instrument was done using test-retest method. Also five trained research assistants were used in the administration of the questionnaire. Findings from the study indicate that attitude, low self concept, culture, beliefs, and societal norms among others play significant role in influencing Girl - Child Education. The study agrees that a sustainable development needs Education to back it up. Recommendations include that the counsellors in the south east should counsel the young girls on attitudinal change, assertive social skills, selfconcept and interest among others.
\end{abstract}

\section{Introduction}

Education is generally acknowledged as one of the greatest processes that can be used to bring about development and sustain it. More so education of good quality is a fundamental human right of all citizens irrespective of sex. This was so recognized and declared as such in 1948 by the United Nations (UN). Education therefore is considered as one of the greatest instruments that any nation can make for its quick economic, social, political and over all human resource development and sustainability. Over the years since the UN declaration, concerted efforts have been made by nations including Nigeria to give basic education to their citizen as a developmental right. For instance, a child has access to education if he/she has unimpeded opportunities, ability and processes by which the individual child is enabled to attain her/his optimal developmental potentials irrespective of factors of ethnic origin, sex, religion, socio-economic background and geographical location UNESCO [17] it is in this context of child's right to education and pursuant of attainment of international mandate on education and training and the millennium development goals that the federal government of Nigeria [7] enacted child's right act, 2003 and the Universal Basic Education Act 2004 which make Basic Education free and compulsory with penalties for defaulting parents and guardians. Despite these efforts and declarations, the education of the girl child in Nigeria has historically lagged behind that of males [18]. Traditionally parents preferred to send their male children to school while females were protected at home to learn household chore from their mothers Njoku [12].

Girl-child education has become a serious agenda in many educational fore and debates in Nigeria, the World's Bank, forum for Africa women educationalists and many other interested organizations and these groups are willing to spend money and time to promote girl child education. This is due to the fact that sustainable human development cannot be effective if half of the human race made up of the girls and women folk remain ignorant, marginalized and discriminated against. Furthermore various government and NonGovernment organizations have realized that for national and international development to be achieved - there is need to promote the education of the girl child.

Girl-child according to UNICEF [19] is a female below the age of 18 years and the broad age group includes non-school age children, pre-primary and primary school children, secondary school children 
and first-year female students enrolled in tertiary educational institutions. The low education enrolment of the girl child has benefits fainter of concern to governmental and non-governmental organizations, teachers, counsellors and administrators. This is due to the fact that education empowers an individual to utilize his/her potentials for personal, collective and national benefits. Therefore, the girl child education is a powerful instrument for the enhancement of growth, development and sustainability of any nation. Furthermore the major universally accepted objective of any system of education by Hart and Rogers [8] are to equip the learner with necessary skills that would ensure his/her livelihood, help develop her/his powers to contribute to the development of the society and socialize the individual into traditional and moral values of his/her society. This lack of the girl child education in our society is evident in the number of representation in all sectors of our economy, such as Health, education, Industry, among others.

Some researchers such as Ohia [15], Njoku [12], Njoku [11], UNICEF [19], Ohia and Azikiwe [16], Nicola, Elizabeth, Cooke and Banke [10], FGN/UNICEF [6] and Irhiam, [9] had attributed the impediments to education and training of the girl child in Nigeria to high cost of schooling, poverty, religion, materialism, child worker, parental and child dissatisfaction with education offered by the school; child trafficking, fear of failure in school work, culture of male references, early marriage, teenage pregnancy, child unfriendly school environment, lack of school health facilities, learner sickness, prolonged teachers strike, low teacher commitment, sexual harassment, limited employment opportunities for school leavers, peer pressure and lack of counselling. It is in the above context that the girl child education for national development and sustainability in Nigeria is examined. It is also seen as a critical means of building and strengthening the country's developmental efforts. More so mobilizing this group (women and girls) whose problems are unique may add dimensions to sustainability and development of Nigeria including south east States. Since girl child education is a vital tool for national development, there is need for more girls to be involved in education Child welfare and poverty in Nigeria [4] and Nwosu [14] observed that counselling and employment of good and quality teachers are some of the result oriented means of ensuring effective education. Ekoja and Adole [5] observed that for these girls to excel effectively, counselling them is needed in the area of projecting good role models, being resourceful, enhancing creativity and life skills in them among others. Furthermore Anagbogu and Nwokolo [3] asserted that mentoring which is a guide to effective counselling will go a long way in motivating these girls to go to school. Anagbogu and Nwokolo [2] opined that counselling is geared towards helping the individual to discover herself, her potentials, abilities, capabilities, talents, interest and strengths as well as utilizing the knowledge to take vital decisions that will help her to adjust and contribute meaningfully to the environment now and in the future. This is with a view to address the girl child education in South East States, Nigeria which has been a major cause for concern.

\section{Statement of the problem}

In Nigeria today the girl child is currently faced with numerous formidable difficulties in the areas of survival, protection, socio-political participation, psychosocial an intellectual development and these indices of human development are beyond the control of the child and therefore needs the adult members of the society to attain these indices through education. For instance these girls are not protected from the ills in the society such as early marriage, teenage pregnancy, street hawking, child labour, they are often seen either roaming the streets, waiting to be hired for labour or begging in motor parks where they receive all sorts of abuse from touts or engage in one form of economic activity among others when they should be in school. This has been a source of worry to the counsellors, teachers and educationists among others and if nothing is done these girls will grow to be nonentities in the society and there will be no opportunity for them to contribute their own quarter to the national development. The paucity of girl child in school is indeed a problem which motivated the researchers to empirically establish that counselling the girl child for education has a role to play in motivating the girl child to excel in various areas of endeavour for the sustainability and development of South East, Nigeria. It is against this background that the researchers were motivated to embark on this study

Therefore, the main objectives of the study are to proffer some counselling strategies for the girl child to imbibe and excel in education.

Two Research questions guided the study.

- What are the impediments to the girl child education in the South East, Nigeria?

- What are the counselling strategies for sustainability and development of the girl child as perceived by the counselors.

\section{Method}

The study is a descriptive survey design. This design is ideal because it involved collecting and describing data obtained from a sample of population. The study was carried out in the South 
East States of Nigeria consisting of Anambra, Abia, Ebonyi, Enugu and Imo states. A sample of five hundred counsellors was randomly selected from all the counsellors in the states, that is 100 counsellors from each state and on the whole 500 counsellors from the 5 states were selected. The instrument was researchers' developed questionnaire of 51 items. The instrument was validated by two lecturers in Guidance and counselling and two in measurement and evaluation. Feedback was given regarding question clarity, comprehensiveness and acceptability and all their corrections were affected in the final version of the instrument. A reliability co- efficient of 0.80 was established using test- retest method. The researchers used direct contact approach in collecting data from the counselors and they employed the services of five research assistants, one from each state to facilitate the work. The data collected were analyzed using statistical tools. Responses for the research questions were answered using mean ratings. Any item with the mean of 2.50 and above was accepted as agreement with the statement while any mean below 2.50 was rejected.

\section{Missing Panels}

Depictions of triple jeopardy in popular visual culture are generally scarce or unavailable, signifying that the process of making new accurate representations of this population is imperative. People who identify with triple jeopardy can find reward in the experience of making new representations and contributing to a more accurate understanding of their identity. Dewey [7] explains that experience is rendered by means of fusing old meanings and new situations that ultimately transfigure both, resulting in imagination. Through an equitable art education curriculum tailored to foster young imaginations, my research participant, Tiffany, and I represent difference by co-authoring a graphic novel. When John Dewey specifically acknowledges that individuals contribute according to their capacity, he compels educators to be a part of a democratic pedagogy, and to encompass equitable curriculum design that unifies individual efforts and social interest [6]. This framework applied to my study takes the form of a graphic novel co-authored by two Black women labeled with disabilities.

My research surrounding the identity of students with disabilities has brought about this graphic novel project that adds to the growing collection of scholarly work on African American women in comics and comics made by people with disabilities with the goal of disrupting readily accepted conceptions of normalcy and ability for historically marginalized identities. Beauvoir questions the assumptions of the politics of difference and acknowledges the abilities of "others" to include the ability to move across various social categories [1], which I see as taking ownership over the identities and agency of a person with triple jeopardy. Social categories such as gender and race are informed by culture, with policymakers branding labels of "other" so fluently that the United States needed enact amendments less than 150 years ago to disregard Blacks as being $3 / 5$ ths of a person, and only 25 years ago for people with disabilities.

Women of color have been cast as other, whether the second sex or $3 / 5$ ths of a human, these outdated terms reflect partial depictions that the disabled population has faced during majority of United States cultural history. Combining the graphic novel medium with personal narratives reveal ways in which Black women with disabilities strategize and self-advocate in order prevail through transitions during arduous life events. These self-advocacy strategies can be incorporated into the classroom curricula to honor individual lifestyle preferences and to support independence. Personal choices that may arise as an art student represents meaningful events in her high school experience are being realized through this democratic and feminist curriculum framework.

\section{Creating the Autoethnographic Novel}

A graphic novel has the potential to change perceptions and investigate populations often disempowered or invisible in a culture [16]. Using an autoethnographic case study approach to conduct my study allows the qualitative research to be practice-based and problem-specific. The graphic novel medium helps me answer whether sequential art forms that address disability occupy a space where text and image have successfully represented Black women with disabilities as we deconstruct the events shared by my participant through participant observation and artifact creation The driving force in this project is the belief that art making is the best way to tell this complex narrative in a richly complex sequential art form as means of investigating triple jeopardy.

Creating a graphic novel focused on identity involves incorporating facets of my research participant, Tiffany, along with my Black feminist lens overlapping with an exploration of making disability visible. The graphic novel is an authentic, often referred to as secondary, not quite fine art, and not quite literature [13], echoing the triple identity label that black women with disabilities encounter. The nature of my relationship to the case study participant significantly impacts the shaping of the research design for this project. This project was inspired from the daily occurrences that take place in and around the art classroom to a person with a disability. 
Tiffany was a student, Tiffany, now a high school graduate who holds multiple professional certificates, was born with a partial right arm. Tiffany has been wearing prosthetics for the majority her life, yet in an interview states that she does not consider herself to be disabled. I shared Kaisa Leka's [14] graphic memoir I Am Not These Feet with Tiffany. She confirmed similar frustrations and successes related to being a woman who wears a prosthesis, which inspired her to narrate parts of her life, which I have sketched in and out of sequence. We are now in the starting phase of co-authoring our own graphic novel. Tiffany explains it is imperative to share with the community of young adults who are labeled as being disabled for purposes of challenging what is considered a normal woman's life. By coauthoring a graphic novel with Tiffany, we reflect on our experiences in art education together.

My autoethnographic research employs three kinds of data collection; interviews, observation, and artifacts are sources of my critical inquiry to the triple jeopardy art student. These sources in turn produce three kinds of data: quotations, descriptions, and excerpts of documents, resulting in one product a narrative memoir script. This narrative memoir script can include charts, diagrams and additional artifacts that help to tell our tale. The script will be shared with an illustrator that Tiffany and I both choose to best illuminate our narrative.

I use the approach of being a participant-observer so that my participant can drive open-ended interviews in the direction of her concerns and ascribe meaning to the events of her daily high school routine. I reflect on the themes generated during multiple interviews to see how relevant issues of the participant's high school experience manifested in the art classroom. The notes, transcripts, and film are analyzed during the data collection phase for emergent questions. Once the data collection is complete it is coded and analyzed for emergent themes. While having multiple interviews with my participant, discoveries surrounding the triple jeopardy experience is collected and transcribed into an autoethnographic script for use in a graphic novel - a sub-genre that I plan to refer to as an autoethnographic novel - to be shared with a black female illustrator who creates accompanying visual artwork.

After the graphic novel is complete and available to share while I conduct a follow up interviews with my participant to gauge our thoughts on the success of the project. With this endeavor, my goal is to determine if the co-creation of a graphic novel empowers triple jeopardy art students in a society that places negative values on labels of being a woman, having a disability, and being black.

\section{Denouement}

Conveying personal narrative through the graphic novel medium has become a worthy endeavor for individuals of varying demographics who aspire to document, connect, and validate their life experiences. The medium of the graphic novel provides recognition to habitually silenced narratives and generates a space for commentary regarding normalcy, beauty, and ability-issues worthy of deliberation. Aspects of a privilege, the changing relationships between healthcare professionals, families, community, and self-identity unfold page by page; humorously lighthearted daily activities and deeply personal affirmations are made in the halls of a high school. Graphic novels about black women with disabilities does more than bring one story to life for a specific population, it stimulates an awareness that comics are an accessible medium that is inclusionary to a wide age and ability range to people. Encouraging students to redefine identity labels by introducing graphic novels spreads noteworthy fragments of the human experience resulting in personal exploration in an accessible and enjoyable object of visual culture.

The outcomes of this research study and joining art project have scholarly implications towards further investigations of identity regarding the lived experiences of young black women with disabilities.

When redefining disability as a temporary state of being, a prosthesis can be more than a physically connected apparatus, and the act of participating in art creation may facilitate a positive self-reflection as well as solidarity. Utilizing graphic novels to represent meaningful events in her life experience, combined with personal narratives may reveal ways in which Black women with disabilities strategize and self-advocate in order to prevail through transitions during a typical school day or even through an arduous life event. As an act of selfadvocacy, creating a graphic novel can be incorporated into the classroom curricula to stimulate rich conversation on subjects of disability, normalcy, and other socially constructed concepts that divide us as a people.

The outcome of creating this graphic novel may be a catalyst to including black women with disabilities in forms of popular media. Both educators and students will have access to the completed graphic novel, with an online version ensuring that individuals of all abilities may obtain and have access to its content. The graphic novel medium is widely received in school-aged populations and will be made available at no cost so that monetary issues do not hold back prejudices from being dislodged and replaced with understanding. With this project and research, I highlight the intersecting relationships between ability, gender, and race through the creation of the 
novel. The creation and focus honor the individual lifestyle preferences made by two black women labeled with disabilities, but can resonate in the minds of a multitude of individuals who lack support in asserting their independence and personal empowerment.

\section{References}

[1] Adkins, A. (2013). Black/Feminist Futures: Reading Beauvoir in Black Skin, White Masks. South Atlantic Quarterly, 112(4), 697-723.

[2] Allen, W. (2006). It's my choice. Minnesota Governor's Council on Developmental Disabilities, 82-83.

[3] Annamma, S., Connor, D., and Ferri, B. (2013). Dis/ ability critical race studies (DisCrit ): theorizing at the intersect ions of race and dis/ ability, Race Ethnicity and Education, 16:1, 1-31

[4] Bandura, A. (1986). Human agency in social cognitive theory. American Psychologist, 44 (9), 1175-1184.

[5] Connor, David. (2009). Creating cartoons as representation: Visual narratives of college students with learning disabilities. Educational Media International, 46(3), 185-205.

[6] Danforth, S. (2008). John Dewey's contributions to an educational philosophy on intellectual disability. Educational Theory; 58, 1.

[7]Dewey, J. (1934). Art as experience.

[8] Ferri, B., and Connor, D. (2006). Reading resistance: Discourses of exclusion in the desegregation and inclusion debates. New York: Peter Lang.

[9] Gabel, S. (2005). An Aesthetic of Disability. In Disability Studies in Education: Readings in Theory and Method (Vol. 3). Peter Lang International Academic.

[10] Gabel, S. (2005). An Aesthetic of Disability. In Disability Studies in Education: Readings in Theory and Method (Vol. 3). Peter Lang International Academic.

[11] Gillborn, D. (2015). Intersectionality, critical race theory, and the primacy of racism: Race, class, Gender, and disability in education." Qualitative Inquiry 21 (3): 277- 287.

[12] Harry B., and Klingner, J. (2006). Why are there so many minority students in special education: Understanding race and disability in schools. New York: Teachers College Press.

[13] McCloud, S. (1994). Understanding comics: The invisible art. New York: HarperPerennial.

[14]Leka, K. (2008). I am not these feet: Kaisa's diary 5: a graphic novel (5th ed.). Helsinki: Absolute Truth Press.
[15] Losen, D., and Orfield, G. (2002). Racial inequality in special education. Cambridge, MA: Harvard Education Press.

[16] Moeller, R. (2011). “Aren't These Boy Books?”: High School Students' Readings of Gender in Graphic Novels. Journal of Adolescent and Adult Literacy 54(7).

[17] Walton, D. (2011). What's a leg got to do with it?: Black, female and disabled in America. Barbara Faye Waxman Fidduccia Papers on Women and Girls with Disabilities. Center for Women's Policy Studies.

[18] Wexler, A. (2009). Art and disability: The social and political struggles facing education (1st ed.). Palgrave Macmillan. 